\title{
Article
}

\section{Practical reasoning in political discourse: The UK government's response to the economic crisis in the 2008 Pre-Budget Report}

Fairclough, Isabela and Fairclough, Norman

Available at http://clok.uclan.ac.uk/3417/

Fairclough, Isabela ORCID: 0000-0001-6718-2636 and Fairclough, Norman (2011) Practical reasoning in political discourse: The UK government's response to the economic crisis in the 2008 Pre-Budget Report. Discourse \& Society, 22 (3). pp. 243-268. ISSN 0957-9265

It is advisable to refer to the publisher's version if you intend to cite from the work. http://dx.doi.org/10.1177/0957926510395439

For more information about UCLan's research in this area go to http://www.uclan.ac.uk/researchgroups/ and search for <name of research Group>.

For information about Research generally at UCLan please go to http://www.uclan.ac.uk/research/

All outputs in CLoK are protected by Intellectual Property Rights law, including Copyright law. Copyright, IPR and Moral Rights for the works on this site are retained by the individual authors and/or other copyright owners. Terms and conditions for use of this material are defined in the policies page.

\section{CLoK}

Central Lancashire online Knowledge www.clok.uclan.ac.uk

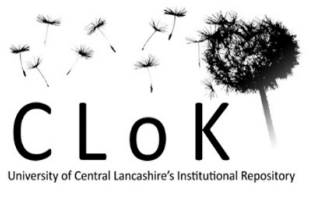


Paper for DISCOURSE \& SOCIETY

Title: Practical reasoning in political discourse: the UK government's response to the economic crisis in the 2008 Pre-Budget Report

Authors:

Isabela Fairclough (University of Lancaster)

Norman Fairclough (University of Lancaster)

Version number: 2. Date: October 18, 2010

Address: University of Lancaster, Department of Linguistics and English Language, LA1 4YT, UK.

Address for proofs: 29 Grasmere Road, Lancaster LA1 3HE, United Kingdom

Email: i.ietcu-fairclough@lancaster.ac.uk, n.fairclough@lancaster.ac.uk

Short title: Practical Reasoning in Political Discourse

Total Word Count: 13900 


\begin{abstract}
This article focuses on practical reasoning in political discourse and argues for a better integration of argumentation theory with Critical Discourse Analysis. Political discourse and its specific genres (e.g., deliberation) involve primarily forms of practical reasoning, typically oriented towards finding solutions to problems and deciding on future courses of action. Practical reasoning is a form of inference from cognitive and motivational premises: from what we believe (about the situation or about means-end relations) and what want or desire (our goals and values), leading to a normative judgment (and often a decision) concerning action. We offer an analysis of the main argument in the UK Government's 2008 Pre-Budget Report (HM Treasury, 2008) and suggest how a critical evaluation of the argument from the perspective of a normative theory of argumentation (particularly the informal logic developed by Douglas Walton) can provide the basis for an evaluation in terms of characteristic CDA concerns. We are advancing this analysis as a contribution to CDA, aimed at increasing the rigour and systematicity of its analyses of political discourse and as a contribution to the normative concerns of critical social science.
\end{abstract}

Key words: argument evaluation, argumentation scheme, argumentation theory, critical discourse analysis, critical questions, deliberation, economic crisis, informal logic, political discourse, means-goal reasoning, practical reasoning, Pre-Budget Report, strategy, UK Government 
Bio-notes

Isabela Fairclough was until recently Associate-Professor and Coordinator of the MA Programme in Discourse and Argumentation Studies at the University of Bucharest. She is currently Visiting Research Fellow at the University of Lancaster, while teaching at the Lancaster University International Study Centre. She has published two books with the University of Bucharest Press and articles in Argumentation, Discourse \& Society, Journal of Language and Politics, Journal of Language in Capitalism, etc., all in the field of argumentation theory and CDA, dealing mainly with political discourse in post-communist Eastern Europe (some of these under the name of Isabela Iețcu).

Norman Fairclough was Professor of Language in Social Life at Lancaster University until his retirement in 2004, and is now Emeritus Professor, Honorary Research Fellow in the Institute for Advanced Studies, and Deputy Director of Cultural Political Economy Research Centre. He has published extensively in the area of critical discourse analysis, including the more recent books Analysing Discourse: Textual Analysis for Social Research (Routledge 2003), Language and Globalization (Routledge 2006) and a radically revised second edition of Critical Discourse Analysis (Longman 2010). 


\section{Introduction}

The focus of this article is textual analysis within Critical Discourse Analysis (CDA). We argue for a systematic approach to analysis of argumentation in political discourse and we focus on a particular argumentation scheme, practical reasoning. In what follows, we focus on a corpus of thirteen policy-making texts, the British Pre-Budget Reports delivered annually, between 1997-2009, to the House of Commons by the Chancellor of the Exchequer, and we offer a detailed analysis of the November 2008 Report, which was an important stage in the development of UK government strategy for responding to the crisis. This article is part of our research into political responses to the current financial and economic crisis (see Fairclough and Fairclough forthcoming a, b).

This focus on practical reasoning in political discourse is a new focus in CDA. Because politics is pre-eminently a realm of action, where judgments and decisions about what to do are made and defended, the type of reasoning that primarily characterizes political discourse is practical reasoning. In our view, CDA has so far paid little attention to the primarily argumentative structure of political texts. Although some discourse-analysts, particularly the Discourse-Historical Approach (Wodak et al 1999, Reisigl and Wodak 2001, Wodak 2009), have regularly listed argumentation as one of their concerns and made extensive analytical use of the Aristotelian notions of topos and fallacies in critically assessing large corpora of data, it is safe to say that there has been so far no systematic attempt to identify, reconstruct, analyze and, on this basis, evaluate any particular argument in texts, or to undertake a principled critical discussion of argumentation in terms of the analytical frameworks of any of the major contemporary theories of argumentation. In particular, there has been no attempt to look at arguments in terms of fundamental concepts such as deductive validity, inductive force, deductive and inductive soundness, persuasiveness, rational persuasiveness, etc. - the familiar stock-in-trade of any 'critical thinking' or informal logic textbook. Neither has there been, to our knowledge, any attempt so far in CDA to investigate practical reasoning and practical arguments, in political or any other type of discourse. ${ }^{1}$

Our focus on argumentation in political discourse may seem open to a common but (we think) seriously misplaced objection. Politics - the argument often goes - is not the realm of argumentation and reasonableness, decisions are actually taken much of the time on the basis of who has the power rather than on the basis of reasoning. This is, of course, not a 
valid objection to the claim that argumentation (and practical reasoning) is a fundamental part of politics, and seems to spring from a confusion between argumentation and democratic deliberation: because a lot of what goes on in politics is not democratic deliberation, then allegedly - it is not argumentation either. It should be clear that, in whatever way a claim about what should be done is reached (behind closed doors, through democratic public deliberation, or by manipulating public opinion), as long as normative claims and decisions are justified by reasons (even by 'bad' reasons, e.g., unacceptable, irrelevant or insufficient reasons), practical reasoning (and argumentation more generally) constitutes an integral part of political discourse. Being critical of the quality of public space dialogue or of some versions of 'deliberative democracy' (Dryzek 2000) is not one and the same thing as denying that this dialogue is fundamentally argumentative in nature.

A related and equally misconceived objection has to do with the distinction between emotion and reason in politics. Because it is often obvious that emotions play a large part in the way people come to a conclusion or decision for action in the political field, then allegedly - politics is often not the realm of reasoning but of 'passions' and this is, allegedly, evidently undesirable. This negative view of emotions and the alleged desirability of decision-making processes based solely on 'reason' are based on a fundamental misunderstanding of the way in which desires and emotions enter the practical reasoning process. More precisely, it is mistakenly assumed that desires, emotions and values cannot legitimately enter as premises in a process of reasoning, in other words, that a normative conclusion should be reached solely on the basis of belief-type premises embodying calm, detached 'reason'. To put it differently, that the world of human emotional concerns (what what we care about, what we value) has no place in reasonable argumentation. We address these confusions in our forthcoming book, yet the structure of practical reasoning we outline below should be enough to show that our desires, values and emotions are necessarily premises in practical arguments: without this motivational and emotional investment, no belief could ever prompt us to act one way or another, simply because nothing would really matter to us. In other words, our capacities for representing the world and our emotional dispositions act together to motivate us to act (Blackburn 1998).

There are, of course, reasonable and unreasonable appeals to 'passions' in arguing for a claim, and in saying that desires, values and emotions are indispensable premises in practical reasoning we are not saying that argumentation drawing on these motivational premises is always reasonable but only that it is not inherently unreasonable or unsound, as 
is often mistakenly assumed in CDA. Contemporary argumentation theory (Walton 2008) does not treat emotional appeals as fallacious, unless they are irrelevant to the claim or are used to disguise the absence of relevant arguments. Indeed, to treat premises grounded in emotion, desire and evaluative attitudes as inherently problematic would be nonsensical as far as arguments for action are concerned, as all such arguments have by definition a motivational component and action results from the coupling of belief with what we want or value.

\section{The structure of practical reasoning}

Practical reasoning (embodied in practical arguments) is reasoning about what to do (as opposed to reasoning about what the case is, so-called theoretical reasoning) and attempts to motivate us (or give us good reasons) to act. The study of practical reasoning is closely related to moral philosophy (ethics) and it is in this branch of philosophy that most work on practical reasoning has been accomplished to date. For a very useful survey of developments since the 1980's see Millgram (2001), for older approaches see Gauthier (1963) and Raz (1978); for an understanding of the relationship between practical reasoning and various types of ethical frameworks, including decision-making frameworks, see Millgram (2005) and Audi (2006, 2009); Audi (2001) provides a unified account of practical and theoretical rationality, from a double perspective - moral theory and epistemology. In the field of argumentation theory, the most significant contributions belong to Walton (2007), who defines practical reasoning as a defeasible argumentation scheme, leading to a conclusion that is provisionally acceptable subject to the asking/answering of appropriate 'critical questions' (Walton 2007: 33). An excellent account of practical reasoning, connecting its normative criteria to Habermasian 'communicative rationality', can be found in Bickenbach and Davies (1998).

Practical reasoning arises in response to problems which confront us as agents in the world. Typically, practical reasoning involves arguing in favour of a conclusion (claim) that one should act in a particular way as a means for achieving some desirable goal or end. Thus, practical reasoning takes a goal (for example, something you want) as major premise and a means-goal conditional proposition as minor premise and concludes that, given the goal and given that a certain action is the means to achieving that goal, the action in question should be 
performed. The action, in other words, is intended to lead from the (undesirable) set of present circumstances, needing transformation, to the desired end. In reasoning practically towards a normative claim for action, we are therefore reasoning from cognitive and motivational premises (from beliefs and desires). This is Audi's 2006 cognitive-motivational account. $^{2}$

We adopt an instrumentalist approach to practical reasoning, which regards all reasons for action as means-end reasons. Instrumentalism rests on a mental ontology of beliefs and desires: figuring out what to do is a matter of determining how to achieve one's goals or satisfy one's desires. Reason's role in the process is instrumental (to inform us about available means towards our goal, about what is possible in the context, etc.) - but not to evaluate or choose the goals as such: in any context of reasoning about what to do, our goals (desires) are given. However, an instrumentalist view is not incompatible with reasoning about goals or ends: in a different context, governed by a different goal, it is possible to question how and whether any previously given goal fits in with or serves this other goal. If my goal is to make more and more money, then - given the goal - various actions may be means towards that end. But if I also have the goal of living a certain kind of stress-free life, then I can ask how these two goals fit in with each other, and perhaps which is or should be my overriding goal.

Practical reasoning is pervasive in everyday life, as well as in politics, in all contexts where decisions on what to do need to be taken, often under circumstances in which the right or best course of action is unclear or contentious. Politics is centrally about decision making and decision making is effected mainly through practical reasoning, which can be embedded in various types of interaction, e.g. public or private deliberation, negotiation, debate. We think that an instrumentalist approach is well supported by the logic of political discourse: various types of political action that are defended in political discourse are means towards the realization of desirable political goals, seen as states of affairs or modes of social organization informed by various moral-political values (e.g., justice, equality, freedom). ${ }^{3}$

Most often, practical reasoning occurs in a problem-solution context. Typically, argumentation starts with a description of the situation as a 'problem' and tries to find a 'solution' to (a 'means' of) overcoming the problem. While some practical arguments emphasize the problem-solution relation (e.g., 'in these difficult circumstances, we should do $\mathrm{x}$ '), others emphasize the means-goal relation ('if we do $\mathrm{x}$, then we will achieve our aims'). In a context of uncertainty and/or risk, where several alternative courses of action are 
conceivable, practical arguments try to balance a number of variables (situation, goals, possible costs and benefits, but also moral considerations, which may override cost-benefit calculations) to arrive at or justify a certain type of action (or solution) as the right one.

Walton (2007) discusses two types of practical reasoning: instrumental and valuebased (normative). The latter contains an evaluative statement (a Value premise) amongst the premises. In our view - which is distinct from the views of the above theorists - the Value premise acts to restrict the set of possible actions that can be taken in a given context, given the goals. If your goal is to divide a cake among ten children, any way of cutting up the cake will achieve that goal, but if the goal is coupled with the value of fairness, then only the action of dividing it into 10 equal slices will be the right thing to do in order to meet both the goal and the value in question. We claim that goals are new states of affairs, new situations that can be brought about by means of action. Typically, the Goal premise refers to a state of affairs in which the agent's desires (needs, wants) are realized, in accordance with certain values or 'concerns'. The agent's goal might be a particular outcome that he desires (because it fulfils some value), or an 'ethical goal' of having done his duty in a given set of circumstances. In the latter case, strictly speaking, the agent might end up not doing what he desires but what he feels bound to do by his duty or by a particular role he feels bound to adopt; nevertheless, we can still speak about a 'desire' or 'concern' to fulfil this duty or role (presumably outweighing other desires).

We often act against our desires and inclinations (as internal, motivating reasons) and in accordance with external reasons (duties, obligations, commitments) which we recognize and accept and care about enough to be moved to action. Some philosophers, inspired by Hume, will then say that overall, our actions are always in the last instance determined by what we desire, value or care about, by our 'concerns' (Blackburn 1998). Consequently, that beliefs have no motivating force on their own until coupled with a sense that something is of value, or that we care about it in one way or another, i.e., reason is merely instrumental in relation to desire. Desires ('concerns') are therefore the ultimate motivators: to say that I have a reason to do something is to say that the reason in question is an internal psychological motive, e.g. I want to act that way. Other philosophers, however, will say that external reasons such as promises we have made or obligations we are under are clearly independent of our desires. They can however become the ground of a desire to do the action in question but the desire derives from the recognition of the obligation and is therefore not basic. Some of our reasons for action are 'desire-dependent' but others are genuinely 'desire- 
independent': we have a reason to act on them (an external reason) even when we choose not to act that way (Searle 2010): we may not care but we ought to care about that reason. ${ }^{4}$

Practical reasoning is sometimes reconstructed as being a deductive or inductive type of argument (Audi 2006, Bowell and Kemp 2005). Like inductive arguments, practical arguments can be good arguments even when the conclusion turns out to be false - i.e. even when it turns out that we had better not have done what (we thought) we had very good reasons to do - if they are supported by rationally acceptable premises which, all things considered, on balance, make it more reasonable to accept the claim rather than reject it (Bowell and Kemp 2005). More often, however, practical reasoning is discussed as a mode of argumentation distinct from either deduction or induction, namely as 'conductive' argumentation (Bickenbach and Davies 1998, Govier 2001). In conductive arguments, the support pattern is convergent, like in inductive arguments, but is not based on the enumeration or accumulation of similar observed examples. The premises are in fact not at all similar to each other, and different considerations, from different if not altogether incommensurable spheres of life, seem to be relevant in deciding what to do. Instead of supporting the claim in a cumulative manner, these premises are balanced against each other and thus cancel or override each other in various different ways for different agents at different times. Walton et al. (2008) also discuss practical reasoning as a distinct argumentation scheme and this is the line we want to take here. In our account, all of the following premises are involved in this complex weighing of reasons: ${ }^{5}$

- $\quad$ premises specifying what end we are pursuing (e.g., what we want or desire) - the Goal premise;

- a conditional warrant that specifies an action (a means) and says that if such-and-such action is performed, the desired end will result - the Means-Goal (instrumental) premise;

- premises that define the initial state or situation (the 'problem') - the Circumstantial premise;

- premises that indicate what values (moral values or other 'concerns') guide the choice of goals and actions: the Value premise;

- optionally, considerations of the 'cost-benefit' or 'efficiency' of action might constitute further premises - Cost-Benefit and Efficiency premises. 
This structure of practical reasoning is crucial to understanding what strategies are. Strategies are developed on the basis of goals, values and beliefs about what the context of action is and what is possible in that context. According to Ricoeur, strategies are ordered chains of means towards desired ends. 'It is this character of desirability that orders, regressively, the series of means envisioned to satisfy it' (Ricoeur 2008: 189). This view captures the necessary 'chaining' of actions oriented towards a certain desirable goal that makes it possible to speak of a 'strategy' rather than a random sequence of unrelated actions, and shows how a goal, once attained, can become a means towards a further goal. But, we argue, it is not only means and goals that are chained together whenever a coherent strategy is pursued. Once achieved, as a result of action, a goal also creates a new context of action and makes it possible to envisage and pursue new goals. Therefore, goals and circumstances are also interlinked, in the sense that present goals (as imagined, desirable futures state-of-affairs), once transformed into reality, become the circumstances of future action towards new goals.

\section{The data: an overview of the corpus}

The Pre-Budget Report (PBR), delivered every year since 1997 by the Chancellor of the Exchequer, is one of the two major economic forecasts that the Treasury is required to present to Parliament (the other one being the Budget Report). The PBR reviews what the Government has achieved since the previous Budget, provides an updated assessment of the state of the economy and public finances and sets out the direction of public policies in the next financial year. Every year, there is an extended report as well as a short text delivered by the Chancellor as a speech in Parliament. In what follows we refer to the speech. Both the full texts and speeches for 1997-2009 are available at http://www.hm-treasury.gov.uk/.

According to the first PBR the problems ('challenges') that Britain was facing in 1997 were: low productivity, insufficient employment and high economic instability. In Gordon Brown's words, for forty years Britain's 'unenviable history' had been one of 'boom and bust', or 'stop-go', marred by a 'failure to take the long-term view'. There was, therefore, a 'real choice' to be made, between, 'muddling through as we have done for decades from one stop-go cycle to another', or 'breaking with our past, burying short-termism and securing long-term strength through stability, sustained increases in productivity, and employment opportunity for all'. The PBR defended the latter choice, as the only way to deliver the 
'national economic objectives' of 'high and stable levels of growth and employment'. The values that guided the actions advocated were 'fairness', 'openness' and 'responsibility'.

In 1998, the PBR announced that the Government had set itself the goal of 'steering a course of stability' against the background of a 'global downturn' originating in Asia and affecting economic growth worldwide. In circumstances of 'global financial instability', in an 'uncertain world', the Government announced 'long term decisions' aimed at 'breaking with short-termism' and 'boom-and-bust', most notably the successful implementation of a 'stable monetary and fiscal framework' - the Code for Fiscal Stability. In 1999, the Government set itself the aim of 'locking in' the stability it had successfully delivered in spite of 'global turbulence' and 'predictions of recession' and argued in favour of leaving behind the 'sterile century-long conflict between enterprise and fairness', between the left and the right, and of 'pursuing both enterprise for all and fairness for all' in order to 'set the course for a Britain of stability and steady growth'.

Successive PBRs recorded various changes in the political and economic situation worldwide. With these changes came more or less marked adjustments in strategies for action and in certain short-term goals, while long-term goals and values remained relatively unchanged. In 2000, the Report started from a positive assessment of the development of the economy between1997-2000. There was 'economic stability', 'low inflation', 'low unemployment' and 'budget discipline'. Based on these factual premises and the stated goal of 'long term prosperity for all', as an objective to be achieved 'in this decade', the Government announced a 'strategy' designed to definitively 'lock in stability' and 'build economic strength', as well as 'ensure a fairer and more inclusive society in which everyone can share in rising living standards'. By 2001, however, the Report began by noting signs of recession everywhere in the world and a slowing down of growth, while by 2002 there was an acknowledgment of the 'worst global slowdown for 30 years'. There were new factual premises: first and foremost, the tragic events of September 11, 2001 and their aftermath, new developments in international security, economic and political 'uncertainty', etc. However, the main objectives and values were unchanged: 'building a stronger and fairer Britain in an uncertain world' (2001), 'rising prosperity for all' (2002), 'building a strong economy and a fair society, where there is opportunity and security for all' (2003 and 2004). In 2003, the Report also made reference to Britain's 'obligations to the war against terrorism and to Iraq' as requiring additional funding, while in 2005, in the wake of the terrorist bombings in London, it made the case for an increase in the budget for national security. 
Between 1997-2006 the Reports are positive and confident. Throughout this period, the Chancellor shows, the Government has met the two fundamental rules in its own Code for Fiscal Stability: budget surpluses over current economic cycles and keeping debt at sustainable levels. In 2006, in the last PBR delivered as Chancellor, Brown noted with satisfaction that, of all major economies, Britain had sustained the longest period of uninterrupted growth and he predicted that growth would continue, with the UK second only to the USA in terms of national income per head.

The 2007 PBR (delivered by Darling) acknowledged 'increased international economic uncertainty' and 'turbulences in international financial markets', originating in the 'American mortgage market', whose global impact was 'as yet unclear'. The British economy, however, had grown for 60 consecutive quarters, inflation and unemployment had remained low, and both fiscal rules had been met. Borrowing was forecast to be $£ 38$ billion in 2007-2008 and was set to fall every year for the next 5 years (the forecast for 2012 was only $£ 23$ billion). The economy was expected to grow by 3\% in 2007 and $2-2.5 \%$ in 2008, with unemployment remaining low, and substantial spending increases were announced in education and public health. The Government thus declared itself well prepared to fulfil its long term goals: 'meeting the aspirations of the British people', delivering 'macroeconomic stability', 'sustainable growth and prosperity', 'fairness and opportunity for all', 'stronger communities and a better quality of life'. Again, the PBR announced additional funding for the wars in Iraq and Afghanistan.

The 2008 PBR marked a radical departure from the usual description of current circumstances, projected objectives and strategies for action. This Report was overtly set against the backdrop of an already full-fledged and 'unprecedented global crisis', caused by 'failings in the global financial system'. In this new context, the economic forecasts of the previous year were discarded, together with their associated plans of action. Economic growth was now forecast to slow to $0.75 \%$ in 2008 , and to $-1.25-1.75 \%$ in 2009 , before recovering to $1.5-2 \%$ in 2010 . Borrowing was forecast to rise sharply in the short term, to $£ 78$ billion in 2008/09 and $£ 118$ billion in $2009 / 10$, i.e. $8 \%$ of GDP. Thus, UK net debt, as a share of GDP, was predicted to increase from $41 \%$ in $2008 / 9$, to $48 \%$ in $2009 / 10,53 \%$ in 2010/11 and 57\% in 2013/14. Consequently, the underlying budget deficit would be $2.8 \%$ of GDP in 2008 and 4.4\% in 2009, but would then decrease yearly until reaching balance again by 2015/16. The 2008 Report made the case for allowing borrowing to rise as the only type 
of action that would protect families and businesses, argued against alternatives, and presented a detailed set of measures geared to this fundamental goal.

In 2009, the PBR was once again set against 'a critical time for our economy and for our country'. Having successfully responded to the 'the biggest financial crisis for over half a century' through a 'set of coordinated steps', the Government's task was now 'to secure the recovery and promote long-term growth'. In order to do so, the Chancellor argued against the view that the budget deficit should be reduced by making cuts in public services, as this would only be 'putting recovery at risk'. The Report defended the interventionist strategy adopted by the Government in the previous year (allowing borrowing to rise), as a 'choice between two competing visions', with different final outcomes - 'securing recovery or wrecking it' - and different underlying values: 'a choice between ambition driven by the values of fairness and opportunity, or austerity driven by an out-dated dogma', between the project of a 'fair society where all prosper and a divided society that favours the wealthy few'. Fairness was again very prominent in the speech, e.g. 'fairness in tax is a crucial part of maintaining fiscal sustainability', which is why 'the biggest burden will fall on those with the broadest shoulders'.

\section{The 2008 Pre-Budget Report: an analytic overview}

We will now focus on the 2008 Pre-Budget Report, presented to Parliament on November 24, 2008, by Chancellor Alistair Darling. Our necessarily limited purpose here is to do what (we claim) is never done in mainstream CDA: a rigorous and principled identification, reconstruction and analysis of argumentation in text, as a basis for critique.

We begin with an overall presentation of the content of the Pre-Budget report, trying to identify the main normative claims that are made and the various types of reasons that support them. We are at the same time trying to offer a rich description of the various alternative formulations in which the same basic content is expressed in various places in the text. It is one of the hallmarks of CDA that linguistic form matters, that choices made as to how to express certain content are of crucial importance. It is of course significant that the circumstantial premises are formulated in terms of 'exceptional' circumstances, or as 'global financial turmoil' - the latter, for instance, suggests similarities with natural calamities where no human agency and responsibility can be imputed. However, such choices (e.g., loaded, 
'persuasive' definitions in the circumstantial premises) can themselves be questioned in terms of a framework for the critical evaluation of arguments, which provides a sounder basis of critique than treating them as isolated features of texts, as often happens in CDA.

For reasons of space we have abridged the text considerably - what is left is mainly a set of repeated formulations of the basic normative argument for action.

Mr Speaker, my Pre-Budget statement today is made against a background of economic uncertainty not seen for generations. These are extraordinary, challenging times for the global economy. And they are having an impact on businesses and families right across the world.

Mr Speaker, in these exceptional economic circumstances, I want to take fair and responsible steps to protect and support businesses and people now - while putting the public finances on the right path for the future.

That is what I will do today. My central objective is to respond to the consequences of this global recession on our country, both now and in the future, so that we are ready to take full advantage of the recovery of the world economy.

My aim is to provide support and protection for families and businesses when they need it most. To maintain our commitment to investing in schools, hospitals and the nation's key infrastructure. And to put in place the measures necessary to ensure sound public finances in the medium term so that as a country we live within our means. Not one single initiative, but a comprehensive plan, to support families, business and the economy.

And because of the wide ranging measures I am announcing today and the many strengths of the British economy, I am confident that the slowdown will be shallower and shorter than would have been the case.

I am also confident that the UK, as an adaptable and open economy, will be well positioned to benefit from a return to growth in the world economy.

First, let me turn to my assessment of the international economy... (...)

(...) But monetary policy - interest rates - on their own are not enough to stimulate the economy, as most people recognise. So we need action now - to boost economic activity - together with the real help I will announce today, to help us emerge quicker. And emerge stronger - from these difficult times, and face the future with confidence. (...)

Mr Speaker, every country in the world is facing the impact of this crisis on their own economy. There is a growing international consensus, although unfortunately not in this House, that we must act now to protect people and to help pull our economies out of recession.

For there is a choice. You can choose to walk away, let the recession take its course, adopting a sink or swim attitude, letting families go to wall. This is the no action plan. 
Or you could, as I have decided, as have governments of every shade around the world, to support businesses and families, by increasing borrowing, which will also reduce the impact and length of the recession.

I will do whatever it takes to support people through these difficult times. That's why my PreBudget Report today represents a substantial fiscal loosening - to help the economy now - with a £20bn fiscal stimulus between now and April 2010, around one per cent of GDP.

Before I describe the detail of how the Government will support people, let me turn to the fiscal framework which will help us ensure fiscal sustainability. The Government introduced the Code for Fiscal Stability in 1998, committing itself to conducting fiscal policy in accordance with a clearly stated set of principles. Our objectives are, and remain, to support the economy, to ensure mediumterm sustainability and maintain public investment. (...) But today Britain - like every other country in the world - faces an extraordinary global crisis, which means significantly lower tax revenues, both now and in the medium term. In the current circumstances, to apply the rules in a rigid manner would be perverse and damaging. We would have to take money out of the economy, making a difficult situation worse.

So it is right that in this Pre-Budget Report we do all we can to support the economy, but also ensure fiscal sustainability in the medium term. This all means that borrowing will be significantly higher than forecast. (...)

If we did nothing Mr Speaker, we would have a deeper and longer recession, which would cost the country more in the long-term. In these exceptional circumstances, allowing borrowing to rise is the right choice for the country, as the CBI, the Institute of Directors, Institute for Fiscal Studies, the IMF, and many others, have all said in recent weeks.

Mr Speaker, we will continue to invest in public services - just as we have done over the last ten years. (...) By continuing to make efficiency savings, we can help fund the action needed to help families and businesses. But we will also ensure spending continues to rise from £584bn last year to £682bn in 2010/11. (...) As businesses and families across the country carefully watch what they spend, it is only right that the Government works even harder to make savings.

Mr Speaker, I now turn to a wide range of measures which I am taking to support the economy and the people of this country. They will help businesses, support home-ownership and boost people's incomes now. Bringing forward capital spending, on major projects, supports jobs and businesses. It is right that, at this time, we re-prioritise investment, from within the existing three-year limits, so that more money is being spent now, when the economy is weaker. (...)

Mr Speaker, this spending will help put money into the economy in the coming months. But to prevent the recession deepening, we also need to take action to put money into the economy immediately. 
I have looked at a range of ways which might achieve this. I have decided that the best and fairest approach is a measure which will help everyone. To deliver a much-needed extra injection of spending into the economy right now. I therefore propose to cut VAT from 17.5 to 15 per cent until the end of next year. (...)

But along with these immediate steps to help businesses and families now, I am also announcing measures to ensure sustainable public finances in the medium term. I considered a number of options to raise revenue in future years. And I have chosen those which are fairest - and affect those who have done best out of the growth of the last decade. (...) So again from April 2011, I intend, only on income over $£ 150,000$, to introduce a new rate of income tax of 45 per cent. This higher rate of tax will only affect the top one per cent of incomes. (...) But I also believe it is right that, as we all benefit fairly from the exceptional measures we take today, we should all share fairly the burden of the future.

Taken together these steps will ensure that there is extra money flowing into the economy now when it is needed most, but we can reduce borrowing as growth returns.

And as a result of my decisions today to provide support now and balance the books in the future, I will bring the current budget back into balance by 2015/16. (...)

Mr Speaker, these are exceptional times and require exceptional measures. It requires action now to help people - and action now to build a stable economy.

We have made our choice. Helping businesses. Helping homeowners. Helping people into work. Boosting incomes.

All only possible because this Government has taken the deliberate decision to support people and businesses through these difficult times.

And I commend this statement to the House. 
The text contains several formulations of the same basic argument on what ought to be done in response to the crisis. The first one occurs in lines 1-14 in our excerpt, where there is a brief description of factual circumstances, immediately followed by an announcement of the Chancellor's 'objectives' or 'aims'. There are immediate goals: 'to protect and support businesses and people now' and 'maintain our commitment to investing in schools, hospitals and the nation's key infrastructure', and there are medium-term goals: 'putting in place the measures necessary to ensure sound public finances'. A distant goal is mentioned, that of eventually being ready to take advantage of 'economic recovery' (later reformulated as 'pulling the country out of the recession'). Given these circumstances and goals, the speaker announces his intention to take a number of 'fair and responsible steps' (i.e., concrete actions) informed by the values of fairness and responsibility. This is the core of any normative practical argument: given certain circumstances and certain goals, a certain type of action, informed by certain values, is advocated in the claim as the right thing to do, and - as in this case - can be followed by public expression of intention (commitment) and decision to act.

From the start, the speaker makes it clear that what is presented is 'not a single initiative' (not a single action) but a ‘comprehensive plan', a 'wide ranging' set of (interconnected) 'measures', intended to take the country from the current (undesirable) situation to a future situation in which the effects of the recession have been overcome. We will refer to this 'plan' as a strategy, emerging from a certain description of current circumstances and informed by certain values and by cost-benefit and efficiency calculations. Arguably, a different strategy for action could be equally successfully defended starting from a different description of the situation, different values, etc., while the goal (a future in which the recession has been overcome) could be the same. In fact, this is what usually happens when two parties deliberate on the best means towards a shared goal: each will try to show that the goal can be achieved only starting from their own premises.

The argumentation advances simultaneously on two distinct planes in this text: there is 'practical reasoning' (what needs to be done, including reports on previous deliberation) and there is 'theoretical reasoning' (what is predicted to happen based on present circumstances). Practical reasoning is mostly reported: the text is a 'report' of a process of collective practical reasoning (deliberation) and is thus at one remove from the original process of practical reasoning itself. This is practical reasoning that has already resulted not only in a normative conclusion (judgment) but also in a collective decision and commitment 
to act that are now being communicated to the public. These facts are not without importance: arriving at a belief as to what the right action is does not always lead to the intention, decision, let alone the public commitment to act in that way.

After this initial formulation of the main argument, Darling turns to a detailed description of the international situation (omitted from our extract): there is a narrative of uninterrupted beneficial growth in the past decade, followed by an account of how the crisis arose and an explanation of its causes ('the root of today's problems are failings in the global financial system'), with narrative and explanation integrated within the overall argument. He then gives an account of what has already been done to combat the effects of the crisis (a 'scheme' to 'recapitalize banks') and an assessment of Britain's strengths in the face of this unprecedented 'global turmoil'. There are also references to the conclusions of the G20 summit in Washington (October 2008), where a 'comprehensive range of measures was agreed to increase transparency of financial activities, ensure better international supervision and prevent excessive risk taking', as well as to domestic decisions 'to make supervision and regulation more effective'.

Lines 21-24 contain the second formulation of the main argument, this time with a more precise formulation of the need to take action (exactly what action is still not specified at this stage): 'So we need action now' (Claim) in order 'to boost the economy' and 'help us emerge quicker' and 'stronger' from these 'difficult times', and 'face the future with confidence' (Goals of various types, more immediate or distant, and Circumstances). This is followed by a section containing the economic forecast for the following years, with recovery already forecast to be underway in 2010 (GDP growth will be once again positive, between $1.5-2 \%)$. The claim, circumstances and goals are reasserted and made more specific in lines 25-27: as 'every country is facing the impact of this crisis on their own economy', 'we must act now to protect people and to help pull our economies out of recession'. At this point, the claim is supported in a different way ('there is a growing international consensus' that this is what we must do, an argument from authority), and a counter-claim is introduced by referring to the existence of an alternative strategy: there is a 'choice' - the speaker says - namely, 'you can choose to walk away, let the recession take its course, adopting a sink or swim attitude, letting families go to wall' (28-29). There is an implicit negative assessment of the value premises that underlie this counter-argument (a 'sink or swim' attitude implies not caring whether families would 'go to the wall', not caring about people's needs). This is what the Chancellor calls 'the no action plan', attributing it to an unspecified group of politicians 
(presumably the Conservatives). The decision he defends is the decision to act, in order 'to support businesses and families by increasing borrowing', which will 'reduce the impact and length of the recession'. So in line 31 the main type of action that will bring about the desired immediate and long-term goals is (finally) explicitly formulated as ‘increasing borrowing'.

Between lines 36-44 the argument addresses a potential objection to the claim it makes, arising from previous strategies (the 1998 Code for Fiscal Stability, which placed limits on borrowing) which are now seen to clash with the course of action advocated. This potential objection is addressed by appealing to the new 'extraordinary' circumstances in which 'to apply the rules in a rigid manner would be perverse and damaging' and 'make the situation worse', not better. In other words, in the new context, the costs of following previous strategies would outweigh the benefits (Cost-Benefit premise). There is an explicit reaffirmation that the overall objectives ('to support the economy, to ensure medium-term sustainability and maintain public investment') have not changed with respect to the past, only the situation and the action strategy have changed. This leads to a reaffirmation of the 'rightness' of the goal of supporting the economy and the people (line 45) and of the chosen action: 'allowing borrowing to rise is the right choice for the country' (lines 49-50). The claim is also independently supported here by an argument form authority ('as the CBI, the Institute of Directors, Institute for Fiscal Studies, the IMF, and many others, have all said...') and by a reassertion of the Cost-Benefit premise ('If we did nothing..., we would have a deeper and longer recession, which would cost the country more in the long-term') - in other words, the alternative strategy will not deliver the goals.

The next few paragraphs (lines 52-56 here) introduce a new line of argumentation, no longer aimed at justifying borrowing, but saving money ('efficiency savings'), to obtain extra funds for supporting families and businesses, coupled with a commitment to increase spending in the public sector. This is a separate argument and a distinct part of the overall strategy and, for reasons of space, we cannot discuss it here. The remainder of the speech (over half of it, omitted here apart from lines 57-76) is devoted to detailing a 'wide set of measures' aimed at 'supporting the economy and the people'. These are measures aimed at helping businesses, home-owners, people affected by unemployment, etc. Some measures are medium term (bringing capital forward to create jobs in infrastructure, re-prioritising investments), but most are immediate measures to 'boost people's income now' (cutting VAT, etc.). Both types and their associated intermediate goals (increased spending power for 
the economy/ for individuals) are explicitly geared to longer-term goals ('preventing the recession deepening').

Two aspects of this second half of the report are of particular interest from an argumentation point of view. First, it is in this part of the text that the main Value premise of the argumentation ('fairness') is asserted repeatedly (there are 8 occurrences of 'fairness' in the report). For instance, 'I have considered a number of options... and I have chosen those which are fairest'; '... as we all benefit fairly from the exceptional measures we take today, we should all share fairly the burden of the future'. There are also two occurrences of 'rightness' in the sense of 'fairness' ('as businesses and families... carefully watch what they spend, it is only right that the Government works even harder to make savings'). Second, there are 7 occurrences of this statement: 'All these measures are only possible because we have taken a deliberate decision to support business, protect jobs, and help homeowners', with occasional variations: 'And this is only possible because I have rejected advice to take no action'. In other words, it is the Government's commitment to a set of goals and values (implicitly different from those of the Opposition) that makes this particular strategy possible: given the circumstances, and given a set of desirable goals and a set of values, and given that it is possible in the context to take certain measures that will meet both the goals and values, the Government should take these measures. By implication, alternative strategies (the 'no action’ plan) would not deliver the goals.

The end of the report sums up the strategy in various ways: 'taken together', these 'steps' will ensure our immediate and more distant goals ('fiscal support now and fiscal sustainability both now and in the future'); if this plan of action is pursued ('and as a result of my decisions today...'), 'I will bring the current budget back into balance by 2015/16' presumably the ultimate goal. The concluding sentences (lines 81-87) review the circumstances ('these are exceptional times', 'difficult times'), claim that 'action' and 'exceptional measures' are needed and restate a number of goals ('helping businesses', 'helping homeowners', 'helping people into work', 'boosting incomes'). The result of the practical deliberation is again reported ('we have made our choice', 'the Government has taken a deliberate decision') and a public commitment is made again to putting it into practice.

\section{Argument reconstruction}


We now focus on the argument in support of action and identify the premises involved. The two diagrams represent the argument as it advanced initially (lines 1-14) and reformulated later (lines 25-51). In the premises we suggest below we are preserving the original wording, while in the diagrams, for technical reasons, we are reformulating the arguments succinctly. ${ }^{6}$

The argument in lines 1-14:

Claim

[The right thing to do is] to 'take ... steps', 'to put in place' a 'comprehensive plan’ of ‘wide ranging measures'.

Circumstances These are 'extraordinary, challenging times for the global economy', 'economic uncertainty not seen for generations', having an 'impact on businesses and families'.

Goals 'My central objective is to respond to the consequences of this global recession on our country, both now and in the future', i.e., short-term goals: 'to protect and support businesses and people now' and 'maintain our commitment to investing in schools, hospitals, key infrastructure' ; 'medium-term' goals: 'to ensure sound public finance', 'putting the public finances on the right path', 'live within our means'; long-term goals: place Britain in a position to 'take full advantage from the recovery of the world economy', 'benefit from a return to growth...'.

Values/Concerns Our [the government's] values are 'fairness' and 'responsibility'. Our (implicit) concerns: people's well-being, people’s 'needs' - we want to support them 'when they need it most'.

Means-Goal (If we put in place this plan of action, then we will achieve the goals.)

At this stage, the argument can be represented as follows (Figure 1) ${ }^{7}$ : 


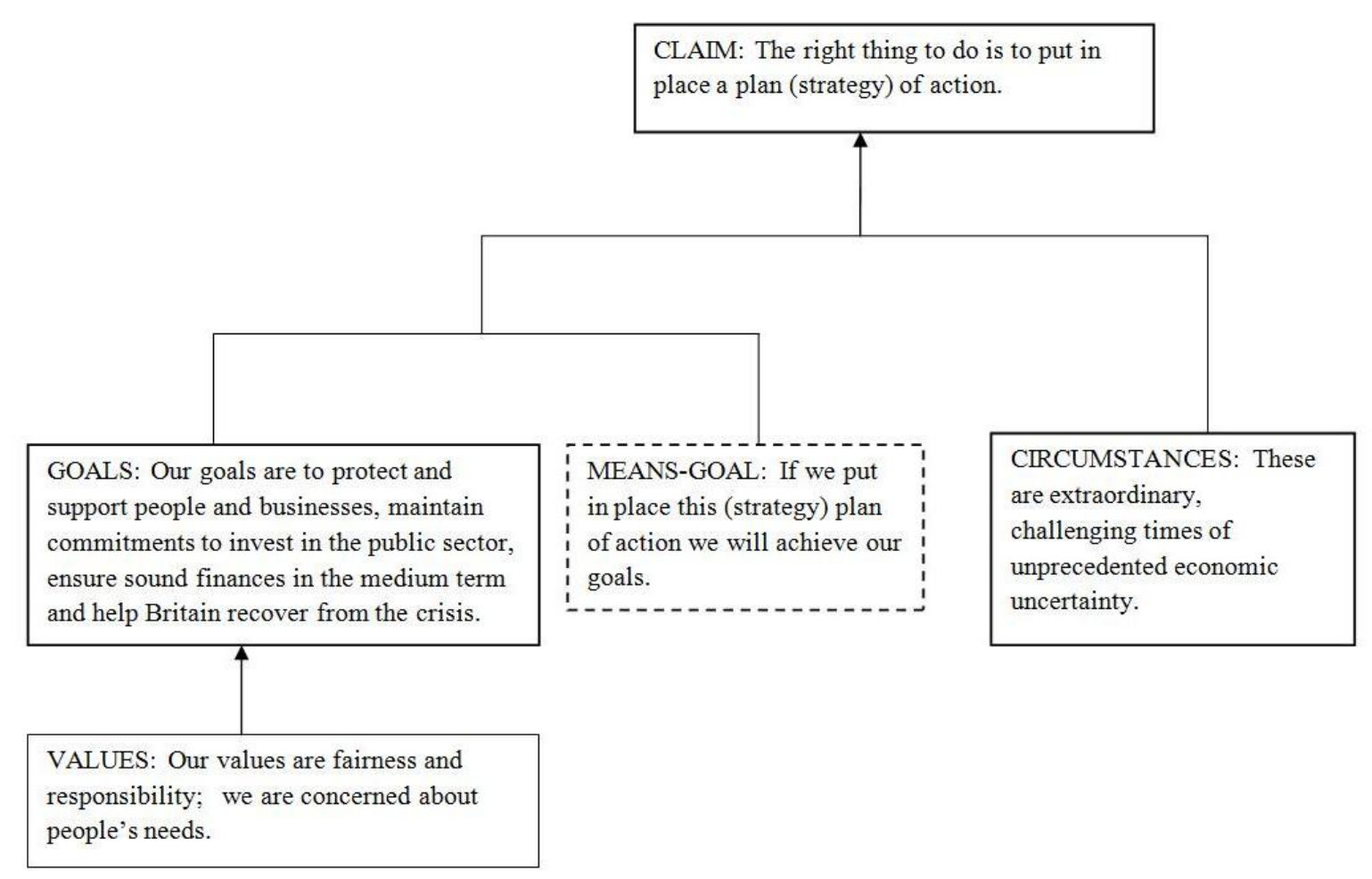

In lines 25-51, the argument is developed to include not only a more explicit reiteration of the claim but also additional support for the claim, in the form of arguments from authority and a clear cost-benefit premise. Most importantly, the speaker also deals with a counter-argument (refutation) and an anticipated objection. We are focusing mainly on lines 25-51 (where the argument is reformulated twice) but, to give a complete picture, we also include in the diagram the 'efficiency' premise implicit in the 7 iterations (in the second half of the text) of this as the best plan that makes the achievement of the goals possible, i.e. the most efficient type of action (i.e., the goal of protecting people would not be achievable otherwise, by some alternative plan of action).

The argument in lines 25-51:

Claim 'We must act now ... by increasing borrowing'; 'borrowing will [have to] be significantly higher than forecast'; 'allowing borrowing to rise is the right choice for the country'.

Argument 'There is a growing international consensus [on this]', 'governments... around the from authority world have already decided'; 'the CBI, the Institute of Directors, Institute for Fiscal 
Studies, the IMF... have all said [this]' \& (If there is a consensus among governments and authorities/ if they have come to this decision, then the claim is right.)

Circumstances 'Every country in the world is facing the impact of this crisis on their own economy', these are 'difficult times'; Britain 'faces an extraordinary global crisis', 'exceptional circumstances'.

Goals Our goals are to 'protect people and pull our economies out of recession', 'reduce the impact and length of the recession'; 'support the economy but also ensure fiscal sustainability in the medium term'.

Values $\quad$ Our values are 'fairness and responsibility'.

Means-Goal (If we act now, by increasing borrowing, we will achieve these goals.)

Cost-Benefit 'If we did nothing, we would have a deeper and longer recession, which would cost the country more in the long-term'. [The costs would outweigh the benefits.]

Efficiency 'And this is only possible because I have rejected advice to take no action', 'All [these measures aimed at protecting the population are] only possible because this Government has taken the deliberate decision to support people and businesses through these difficult times'.

Dealing with Counter-argument (as represented by speaker): the right thing is not to act, 'walk Counter- away', 'let the recession take its course' - the 'no action plan'. [Instead of being argument concerned with people's needs (hence the goal of 'protecting' them), this plan, the speaker shows, is underlain by a 'sink or swim' attitude and will let people 'go to the wall'. Implicitly, this plan does not care for the effects of the recession on people, its human costs will be higher than the benefits, and should be rejected.]

Dealing with The anticipated objection to the government's strategy is that it contradicts the anticipated provisions of the 1998 Code for Fiscal Stability, which placed limits on allowable objection borrowing. The speaker argues that the circumstances have changed and therefore 'to apply the rules in a rigid manner would be perverse and damaging' and would make the situation worse. So, given the new 'exceptional' circumstances and the new goals, and, implicitly, in order for the costs not to outweigh the benefits, borrowing has to rise.

Figure 2 represents the argument as it is formulated at this stage: 


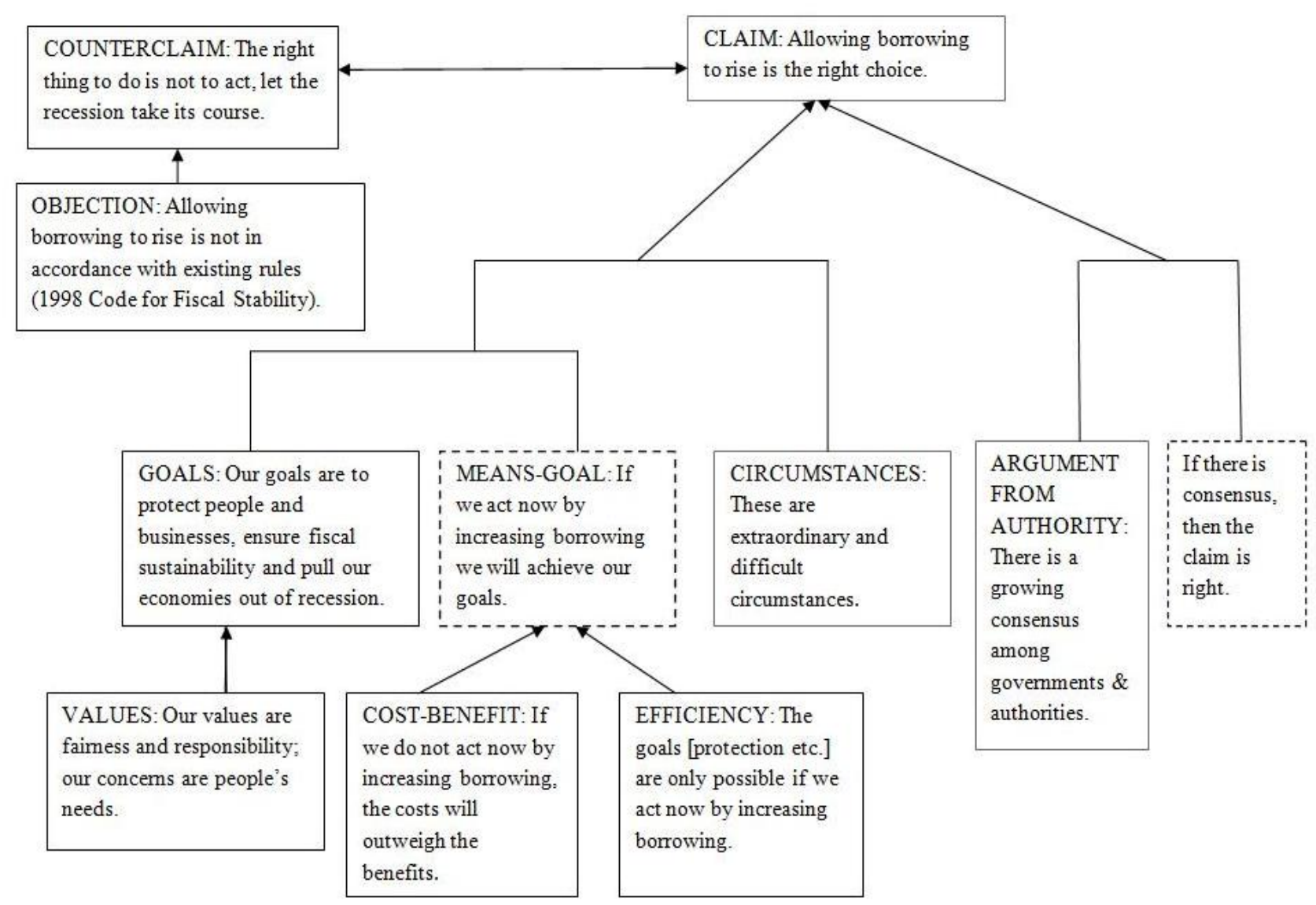

As the diagrams show, practical reasoning is reasoning from the Goal, Means-Goal, Value, Circumstances, Cost-Benefit and Efficiency premises (and optionally, from other premises as well: here, an argument from authority provides independent support, in multiple argumentation). Practical reasoning (and its assessment) means deciding whether, all things considered - given these goals, these values, these circumstances, these cost-benefit probabilities - the claim to action is sufficiently supported. Balancing all relevant considerations is often very difficult to do. Cost-Benefit and Value premises, for instance, can interact in complex ways. Cost-Benefit calculations are often overridden by the Value premise: regardless of costs and benefits to us, a certain course of action may simply be the 'best' because it fulfils some (moral) value. Alternatively, what we may feel is our 'duty' to do may be overridden by cost-benefit calculations. And the situation is complicated further by the fact that, at any one time, we may be under pressure to satisfy different moral obligations, and deciding which should prevail or have more weight is not always straightforward. 


\section{Argument evaluation and its relevance for CDA}

We now briefly address the question of how this approach can contribute to the critical objectives of CDA: would critical discourse analysts gain anything from the (no doubt, considerable) effort of acquiring the analytical framework of argumentation theory? We strongly believe they would, and that CDA analyses would thereby gain in systematicity and rigour. This might help CDA practitioners to avoid criticism of their methods of textual analysis - see for example Zagar's (2009 and forthcoming) critique, from within argumentation theory, of the use of topoi in the Discourse-Historical Approach.

In this article we have focused on analysis of argumentation and we are not attempting to offer a detailed assessment of the argument we have looked at. We only want to suggest a variety of directions of argument evaluation and criticism which this type of analysis can open up. The normative question 'what properties make an argument a good one?' has received various answers from various theorists, depending on whether the approach to argumentation is primarily logical, rhetorical or dialectical. Informal logicians equate a good ('cogent') argument with a 'rationally persuasive' one (Johnson 2000, Govier 2001, Bowell and Kemp 2005). For those informal logicians who have developed theories with a strong dialectical orientation, a good argument is one that (among other things) addresses objections and counter-arguments (Johnson 2000), or withstands critical questioning (Walton 2007, 2008). Pragma-dialecticians talk about 'reasonable' arguments (van Eemeren and Grootendorst 2004) as arguments that have been developed in accordance with a set of procedural discussion rules that ensure maximum opportunity for the critical examination of arguments. Both informal logicians and pragma-dialecticians show in what ways 'rational persuasiveness' or 'reasonableness' is distinct from mere 'persuasiveness' or from 'soundness'. A persuasive argument may not be rationally persuasive, an argument which is rationally persuasive for a person may not be so for another, (rationally) persuasive arguments may not be sound, etc. There is no space to address these subtle and difficult theoretical distinctions here but it should be clear that they are not irrelevant for CDA: questions having to do with ideology (and its 'naturalization'), 'manipulation', or the question why people are often persuaded by arguments which should not persuade them (or so the analyst would like to claim) can be discussed in terms of a normative conception of argumentation. 
Practical reasoning is a presumptive or defeasible argumentation scheme, and the acceptability of the claim depends on how well the arguer can answer a set of relevant critical questions (Walton 2007). In other words, an apparently acceptable practical inference can be defeated by adding a further premise, as a result of critical questioning. Even when the conclusion seems to be reasonably well supported by the premises, we might find ourselves rejecting the conclusion (for instance, at a later date) if, on balance, after considering the possibility of other means or other goals, or after assessing costs and benefits, or commitments we have to values, principles and norms, we find that another course of action is (or would have been) more reasonable. To say that practical reasoning is defeasible or presumptive also means that different agents might come up with a different way of weighing and balancing all considerations, consequently with a different conclusion. In fact, the Labour Government's argument for action in 2008 has already been rejected by the current LiberalConservative coalition government, who - starting from a different assessment of the situation, different goals and values, a different cost-benefit analysis, etc. - have concluded in favour of a different strategy for action, involving mainly austerity measures and an ample programme of cuts. For the current government, Alistair Darling's argument, which we have analyzed above, is a defeated argument, and one which they have seen fit to reject.

Like any type of reasoning, good practical reasoning has to meet normative criteria of premise acceptability, relevance and sufficiency. The sufficiency criterion for practical arguments can be approximated to a Habermasian (1984) ideal of 'communicative rationality' (Bickenbach and Davies 1998). Thus, a practical judgment is sufficiently supported if as many as possible relevant considerations have been entertained and weighed against each other - e.g., how the practical judgment or decision will affect everyone concerned, what other goals and values and different conceptualizations of the context of action are in play and should be taken into account and how these might affect the practical judgment in question, etc. - and the final outcome of this deliberative process points towards the action in question as the better option.

In addition to these normative criteria, various epistemic considerations are also relevant. According to Audi (2006), good practical reasoning expresses a deductively valid (or inductively strong) underlying argument, with premises that are true (acceptable) and justifiably believed, and with a conclusion which is both justifiably inferred from the premises and justifiably held by the agent on the basis of these premises. In other words, good practical reasoning meets logical, material, inferential and epistemic criteria (Audi 
2006: 156-157). For instance, rationalizations - frequently deployed to manipulate public opinion, e.g. justifying the Iraq war on grounds of a desire for freedom and democracy - are not good arguments because they most probably fail the last two criteria, which are both epistemic in nature: most probably, the arguer is not committed to the conclusion on the basis of the premises that he overtly cites but on the basis of other premises (and he may in fact not even believe the overt premises). A similar flaw can be said to affect the main argument in the Pre-Budget Report: is the Value premise (the government's alleged commitment to fairness, its concern with people's needs) actually supporting the claim for action, as put forward by the Chancellor - in the material, epistemic and inferential senses above - or is it just a rationalization, a way of dressing up, in a way that will hopefully resonate well with the public, an altogether different set of less high-minded (more utilitarian, efficiency-driven) concerns? We could argue, for instance, that to adopt a set of measures that is destined to ensure a return to 'business-as-usual', without any substantive reform of the economic system, is ultimately not really proof of a concern with fairness, or that a genuine commitment to fairness would support a different claim for action, e.g. a radical reform of the economic system that led to crisis, so that similar crises might not occur again in the future. We could also suggest that Darling may sincerely believe that allowing borrowing to rise is the right choice, but that he is not committed to this conclusion on the basis of his belief in fairness, but on the basis of other unexpressed beliefs (e.g., the need to rescue the economic system rather than reform it). Such lines of questioning would be made available to the discourse analyst by the analytical framework of argumentation theory.

As we have already said, to say that practical reasoning is defeasible means that it leads to a conclusion that is acceptable subject to rebuttal by critical questioning (Walton 2007, Walton et al 2008). On this view, a set of critical questions can be attached to every argumentation scheme. This is the set of questions that Walton suggests for practical reasoning:

- Are there alternative courses of action apart from the one advocated that would also lead to the goal? (Other-Means Question)

- Is this course of action the most acceptable, the best among alternatives? (Best-Means Question)

- Should other goals be considered? (Other-Goals Question) 
- Is it really possible to do the action in the situation? (Possibility Question)

- What bad consequences of the action should be taken into account? (Side-Effects Question) (Walton 2007: 354, Walton et al. 2008: 96)

If it turns out that there are indeed better means towards the goal, or indeed more reasonable goals that we could set ourselves, or if there are negative effects that we have so far failed to consider, then the inference to the claim is suspended: the best course of action might not be the one we thought the best. However, as Kock (2007a, 2007b) has convincingly argued, a practical argument in the political field cannot be so easily rebutted by critical questions. There will always be other means, other goals, other values, many of these not obviously or necessarily 'wrong', as well as various costs associated with any political proposal. In fact, there are often legitimate arguments on both sides of an issue (an outcome of value pluralism but also of the legitimately subjective way in which various considerations weigh with different people) and an arguer's failure to answer any one critical question in a satisfactory manner will not in itself be enough to discard his proposal for action. A similar argument has been made by Billig (1996). ${ }^{8}$

This is why, in Fairclough and Fairclough (forthcoming a) we develop Walton's basic set of questions to deal with other potential problematic aspects of each of the premises and to address other types of premise, e.g. Circumstantial and Value premises. We can for example question the Circumstantial premise and its relation to all the other premises. We can ask whether the circumstances (the context of action) are defined in a rationally persuasive way, or whether the description of the circumstances is in fact tied to a particular ideology or to particular power interests. Would a different definition of the context support different actions, and be compatible with different goals and different values? Or we can ask whether different other values (other concerns), shared by other social actors, have been taken into account, and whether those concerns are compatible with the stated goals and actions. Is a concern with fairness compatible with what is being done in the name of fairness, namely cuts in state spending as opposed to increasing taxation of banking activities or pursuing tax evasion? Or we can inquire whether the values and goals, as stated, are drawn from particular ideological representations of the world and serving the interests of some groups of people and not others. We can in fact investigate any representation of any premise (circumstances, goals, values, etc.) by asking whether in fact we are not dealing with 
'persuasive', 'biased' definitions (Walton 2007) for which no burden of proof has been undertaken.

These are questions which can be generated fairly mechanically from the account of practical reasoning we are working with, once the structure of practical reasoning has been properly understood and the argument correctly reconstructed. They identify in a systematic and exhaustive way the possible points of entry for criticising practical reasoning, by questioning every possible premise and every relationship of support between premises and claim. Although they are, on the face of it, different from the sort of critical questions that are posed about texts in CDA, we argue that they provide a clear way of linking CDA-type questions to the analysis of argumentation.

CDA contributes a particular focus on discourse and on relations between discourse and other social elements to the various forms of critique pursued in critical social science, including critique of domination and critique of ideology. The analysis and evaluation of argumentation offers a particularly effective way of systematically extending these focuses of critique into analysis of texts. Critique of (practical) reasoning - and indeed critique of discourse more generally - does not in itself constitute critique of domination, but it does pose critical questions which lead into and contribute to analysis of power relations and relations of domination as manifested in particular bodies of texts. Take for instance the questions above aimed at the Value premise. The main value that the Chancellor appeals to is 'fairness'. The question 'Should other values be considered?' brings in for instance the value of justice, and leads into the question of whether and to what extent the government's concern with fairness in its everyday sense is able to dominate public political space at the expense of what for many would be the central issue of value which the crisis gives rise to: what would a just economic system be like? The same question might prompt us to think of the rhetoric of 'fairness' as a convenient facade used to rationalize the pursuit of altogether different agenda - rescuing the neoliberal market system and returning to business-as-usual. The question 'Are the stated values defined in a rationally persuasive way?' provides an opening for critique of the understanding of 'fairness'. For instance, here, an equal sharing of the losses is said to be fair, whereas for many people what would be fair is that those agents (e.g., bankers) with primary responsibility for the crisis should suffer most of the losses. The question 'are the stated goals and actions compatible with the stated values?' provides an opening for a critique of the limited scope of 'fairness', which here goes no further than to mitigate the impact of the recession and does not for instance include the goal of creating a 
'fairer' financial-economic order. To what extent is the latter goal marginalized in public political dialogue? The issue of 'manipulation' also arises here: whether and how particular agents and agencies in public political discourse are able to manipulate others through the use of arguments which are persuasive, although normatively deficient. This can happen in those situations in which an agent (e.g. the government) justifies a certain course of action by appeal to a set of premises, which the audience might have no problem with (e.g. the pursuit of fairness), while in effect the agent's commitment to that course of action is supported by different reasons, and not by those that are explicitly presented to the public (the case of rationalizations).

In ideology critique, critical social science seeks causal explanations of the normalisation, naturalization and institutionalization, as well as pervasiveness and endurance within populations, of particular beliefs and concerns. It seeks to explain them in terms of the structures of material and social relations of particular forms of social life, with such questions as: Why do these particular beliefs and concerns endure over long periods of time? Why do they have powerful resonance for a great many people? Why are they so little challenged? What effects do they have on continuities and changes in social life? Again, critique of practical reasoning does not amount to critique of ideology, but it does show how particular beliefs and concerns shape practical reasoning and, contingently, decisions and actions on matters of social and political importance, and it does pose critical questions which can feed into critique of ideology and anchor it systematically in features of texts. With respect to the questions about the Value premise, for instance, the commonsensical understanding of 'fairness' which the text evokes might be taken to be ideological and to contribute to maintaining an unjust socio-economic system: people who have in no way benefitted from the financial-economic system that has resulted in the crisis and have no responsibility for how the crisis came about are now being asked to share the burdens of fixing up the system in a 'fair' way. Thus the costs of the crisis are distributed 'fairly' amongst the entire population, regardless of huge disparities in resources and unequal moral responsibilities. Particular instantiations of the goal, means-goal or circumstantial premises can be subjected to the same kind of scrutiny: are particular representations of the context of action ideological? Have other representations (or definitions) of the circumstances been taken into account, and if not, why? What significance can we attach to the fact that only certain goals, certain values, or certain means are considered in public policy arguments? 
What would the effects be of allowing other goals, values and means to enter the public debate?

The account we have given of practical reasoning is to be viewed as a part of a wider account within critical social science of the causes of social change. It treats reasons for action (premises in arguments) as one type of cause. Reasons are of course entertained by people, and they are part of the causal powers (Fairclough, Jessop and Sayer 2004) of people as social agents (i.e., their powers to bring about change). But in addition to agentive causes of social change there are structural causes, and CDA is committed to the aim which characterizes critical social science more generally, of trying to clarify how agentive and structural causes relate to each other, i.e., to clarify the dialectic of structure and agency. For CDA in particular, this aim includes for instance trying to clarify the relationship between the causal effects of 'orders of discourse' (structures of a particular sort, see Fairclough 1992, 2003) and of the agency of people as social actors and producers of texts. For instance, in the case of practical reasoning, we have identified beliefs, desires and values as premises in practical reasoning; but an adequate account of causes of social change would need to also ask why particular sets of beliefs, desires and values appear in particular instances of practical reasoning, how for instance they may arise from particular groups or classes of people being positioned in particular social-material relations. This moves us from the agency of people involved in practical reasoning towards structural factors and causes. Among people's reasons for action (beliefs, desires/ values/ concerns) are reasons that express various external (structural, institutional) constraints on what they can do. They have duties, obligations, commitments, for instance obligations to abide by rules and laws and to respect the rights of other people. Analysis of practical reasoning offers the advantage of showing how the power of social and institutional structures manifests itself in the reasons for action that people recognize: structures constrain agency by providing people with reasons for action. We develop this discussion in Fairclough and Fairclough (forthcoming a).

The analysis and evaluation of practical reasoning will not tell us everything about social change; it will not tell us for instance whether action based on this reasoning will be effective in achieving social change, or what other facts about the world will make it succeed or fail to do so. But there are a number of things that such analysis can do. It can highlight the connections among people's values and concerns, their representations of the world, their goals (the way in which they want the world to change) and the actions they conclude are appropriate in order to take them from current circumstances to future desirable situations. It 
can clarify relations between agency and structure, by identifying the way in which agents' arguments draw (selectively) on orders of discourse to justify action, and how these arguments function within their plan of action and within fields of contestation over what action is appropriate, and particularly by showing how structures constrain or enable agency: by providing people with reasons for action. It can place such analysis against the background of public space debate, where arguments based on different sets of premises (different representations of the world, different values, etc.) and advocating different types of action attempt to persuade vast numbers of people of the rightness of their claims. It can offer a principled way of criticizing powerful arguments that are not easily challenged, arguments that draw on dominant discourses and ideologies, at the expense of an impartial consideration of other interests and perspectives, as being unreasonable, as falling short of an ideal of communicative rationality. It can thereby offer a principled way of evaluating decisions made on the basis of arguments which do not come up to the standards of rationally persuasive argumentation. And this represents a substantive enhancement of the capacity of CDA to undertake critical analysis of texts in politics and other social fields.

\section{Conclusion}

In this article we have argued for an integration of CDA with argumentation theory in the analysis of political discourse. We have started from the assumption that political discourse and its specific activities or genres (particularly deliberation, but also debate and negotiation) involve primarily forms of practical reasoning, oriented towards finding solutions to problems and deciding on future courses of action. We have provided an analysis of the main argument in the 2008 Pre-Budget Report and suggested a reconstruction of two versions of that argument. In the last section we have also indicated in what way argument reconstruction and analysis can be systematically used in order to critically evaluate arguments, and how one can avoid textual critique having a subjective or ad-hoc character by grounding it in analysis of arguments and in the normative frameworks of argumentation theory. We have also suggested how analysis of argumentation can enable CDA to address its characteristic concerns in a more systematic and rigorous way and make a valuable contribution to the normative concerns of critical social science. 


\section{References}

Audi, R. (2001) The Architecture of Reason. The Structure and Substance of Rationality. New York: Oxford University Press.

Audi, R. (2006) Practical Reasoning and Ethical Decision. London and New York: Routledge.

Audi, R. (2009) Business Ethics and Ethical Business. New York: Oxford University Press.

Bickenbach, J. E. and Davies, J.M. (1998) Good Reasons for Better Arguments. Ontario: Broadview Press.

Billig, M. (1996) Arguing and Thinking: A Rhetorical Approach to Social Psychology, New Edition, Cambridge: Cambridge University Press.

Bowell, T. and Kemp, G. (2005) Critical Thinking: A Concise Guide. London and New York: Routledge.

Blackburn, S. (1998) Ruling Passions. A Theory of Practical Reason. Oxford: Clarendon Press.

Dryzek, J.S. (2000) Deliberative Democracy and Beyond: Liberals, Critics, Contestations. Oxford: Oxford University Press.

Eemeren, F. H. van (2009) (ed) Examining Argumentation in Context. Amsterdam: John Benjamins Publishing Company.

Eemeren, F. H. van (2010) Strategic Maneuvering in Argumentative Discourse. Amsterdam: John Benjamins Publishing Company.

Eemeren, F. H. van and Grootendorst, R. (2004) A Systematic Theory of Argumentation. The pragmadialectical approach. Cambridge: Cambridge University Press.

Fairclough, N. (1992) Discourse and Social Change. Cambridge: Polity Press.

Fairclough, N. (2003) Analysing Discourse. Textual Analysis for Social Research. London and New York: Routledge.

Fairclough, N., B. Jessop \& A. Sayer (2004) 'Critical Realism and Semiosis', in Joseph, J. and Robe, J.M. (eds) Realism, Discourse and Deconstruction. London: Routledge.

Fairclough, I. and Fairclough, N. (forthcoming a) Political Discourse Analysis. London: Routledge.

Fairclough, I. and Fairclough, N. (forthcoming b) 'Practical Reasoning in Political Discourse. Moral and prudential arguments in the debate over bankers' bonuses in the British press', Proceedings of the Seventh Conference of the International Society for the Study of Argumentation. Amsterdam: Sic Sat.

Fairclough, N. and Fairclough, I. (2010) 'Argumentation Theory in CDA: Analyzing Practical Reasoning in Political Discourse’, in de Cillia, R., Gruber, H., Krzyzanowski, M. and Menz, F. (eds) Diskurs-Politik-Identität/Discourse-Politics-Identity. Tübingen: Stauffenburg Verlag, pp. 59-70. 
Gauthier, D. (1963) Practical Reasoning: The Structure and Foundations of Prudential and Moral Arguments and Their Exemplification in Discourse. Oxford: Clarendon Press.

Govier, T. (2001) A Practical Study of Argument, Fifth Edition. Belmont California: Wadsworth/Thomson Learning.

Habermas, J. (1984) The Theory of Communicative Action. Volume One. Reason and the Rationalization of Society. London: Heinemann.

HM Treasury (2008) 'Pre-Budget Report statement to the House of Commons, delivered by the Rt Hon Alistair Darling MP, Chancellor of the Exchequer', at http://www.hmtreasury.gov.uk/prebud_pbr08_speech.htm, last accessed 25 March 2010.

Ieţcu, I. (2006a). Dialogue, Argumentation and Ethical Perspective in the Essays of H.-R. Patapievici. Bucureşti: Editura Universităţii din Bucureşti.

Ieţcu, I. (2006b) Discourse Analysis and Argumentation Theory: Analytical Framework and Applications. Bucureşti: Editura Universităţii din Bucureşti.

Ieţcu, I. (2006c) 'Argumentation, dialogue and conflicting moral economies in post-1989 Romania', Discourse and Society 17(5): 627-650.

Ieţcu-Fairclough, I. (2008) 'Legitimation and strategic maneuvering in the political field', Argumentation, vol 22: 399-417.

Iețcu-Fairclough, I. (2009) 'Legitimation and strategic maneuvering in the political field’, in Eemeren, F. H. van (2009) (ed) Examining Argumentation in Context. Amsterdam: John Benjamins Publishing Company, pp. 131-152.

Johnson, R. H. (2000) Manifest Rationality. A Pragmatic Theory of Argument. New Jersey: Lawrence Erlbaum Associates Publishers.

Kock, C. (2007a) 'Is Practical Reasoning Presumptive?’, Informal Logic, Vol. 27. No. 1 (2007), pp. 91-108.

Kock, C. (2007b) 'Dialectical Obligations in Political Debate', Informal Logic, Vol. 27. No. 3 (2007), pp. 233-247.

Millgram, E. (2001) ed. Varieties of Practical Reasoning. Cambridge Mass.: The MIT Press.

Raz, J. (1978) ed. Practical Reasoning. Oxford: Oxford University Press.

Ricoeur, P. (2008) From Text to Action. London: Continuum.

Reisigl, M. and Wodak, R. (2001) Discourse and Discrimination. London: Routledge.

Reed, C. and Rowe, G. (2005) Araucaria, Version 3, at http://www.computing.dundee.ac.uk/staff/creed/araucaria, last accessed October 10, 2010.

Searle, J.R. (2010) Making the Social World. The Structure of Human Civilization. Oxford: Oxford University Press.

Walton, D. (2007) Media Argumentation. New York: Cambridge University Press. 
Walton, D. (2008) Informal Logic. A Pragmatic Approach. Second Edition, New York: Cambridge University Press.

Walton, D., Reed, C. and Macagno, F. (2008) Argumentation Schemes. New York: Cambridge University Press.

Williams, B. (2001) 'Internal and External Reasons, with Postscript', in Millgram, E. (ed.) Varieties of Practical Reasoning. Cambridge Mass.: The MIT Press, pp. 77-98.

Wodak, R., de Cillia, R., Reisigl, M. and Liebhart, K. (1999) The Discursive Construction of Austrian National Identity. Edinburgh University Press.

Wodak, R. (2009) The Discourse of Politics in Action. London: Palgrave Macmillan.

Zagar, I. Z. (2010) 'Topoi in Critical Discourse Analysis', Lodz Papers in Pragmatics 6.1(2010): 327.

Zagar, I. Z. (forthcoming) 'The Use and Misuse of Topoi: Critical Discourse Analysis and DiscourseHistorical Approach', Proceedings of the $7^{\text {th }}$ Conference of the International Society for the Study of Argumentation, Amsterdam: SicSat.

Endnotes

\footnotetext{
${ }^{1}$ For some of our earlier attempts to combine argumentation theory with CDA, see Ieţcu (2006a, 2006b, 2006c); for more recent attempts, Iețcu-Fairclough (2008, 2009), Fairclough and Fairclough (2010) and Fairclough and Fairclough (forthcoming b).

${ }^{2}$ In its simplest form, according to Audi (2006: 140), the structure of practical reasoning is the following (where $\varphi$ is the Goal and $\mathrm{A}$ is the action):

(1) major premise - the motivational premise (I want/desire/need/intend $\varphi$ );

(2) minor premise - the cognitive (instrumental) premise: my A-ing would contribute to realizing $\varphi$ (or my A-ing is the best means of realizing $\varphi$, etc.);

(3) conclusion - the practical judgment I should $\varphi$.
}

The conclusion is much more strongly supported if A is 'the best means' of realizing the goal, than if A is merely a necessary condition (for it may be necessary but not also sufficient). 'Best means' would imply here that the Benefits outweigh the Costs, that there is not a more efficient means of bringing about the goal, that the expected value (utility) of the action is very high, etc. However, the conclusion of such an inductively strong argument might still be overridden by some moral principle. Saving ten people by killing one person might satisfy all considerations of utility, cost-benefit, efficiency, yet will be ruled out on the grounds that it violates the rights of the person in question 
(Bowell and Kemp 2005: 207). So the 'best means' to reach our goals may sometimes be an action that scores low on efficiency and cost-benefit analysis but high in terms of compliance with a moral principle. After balancing different concerns, i.e., rights/duties versus cost-benefit, the former may override the latter.

${ }^{3}$ Practical reasoning is the argumentative scheme underlying deliberative discussion, as a type of dialogue or activity type. This paper does not address this very important concept explicitly. The aim of public deliberation is to select a course of action by looking at reasons for and against one action compared with available alternatives. In contexts of deliberation, two or more parties are trying to decide on the best course of action (Walton 2007: 31).

${ }^{4}$ In philosophy, this discussion takes the form of a distinction between internalism and externalism (Williams 2001, Searle 2010), which we explain in our forthcoming book. As far as the distinction between values and desires is concerned, values are different from mere desires in the sense that they are our stable, fundamental concerns. They can inform our desires and our goals or can enable us to take a critical stance with respect to them (Blackburn 1998: 67).

${ }^{5}$ We take the Humean emphasis on 'concerns' as underlying motivation from Blackburn (1998). We are adding the Circumstantial premise (not present in Walton's 2007 account) on the common-sense assumption that no strategy for action can proceed in the absence of an understanding of the initial situation. Both our goals (desires) and the way we describe the circumstances are informed by our concerns: something is a problem or a goal only because of something else that we care about. The Cost-Benefit and Efficiency premises are suggested by Bowell and Kemp (2005), according to whom they are needed in order to make the argument inductively forceful. Clearly, without them the probability of the conclusion coming out true, even from true premises, is not high enough. We think they support the Means-Goal premise, as they increase its probability. In our analysis, as in Walton's, the Value premise supports the Goal premise. Our suggestion is that values restrict the set of actions that are compatible with the goals, seen as desirable states of affairs, by excluding all those which are not compatible with the value in question. I can get rich (goal) by various means, but only some of these means are compatible with the set of moral values I adhere to.

${ }^{6}$ We are grateful to Marilyn Oruwari (University of Bucharest) and Stefan Preoteasa (University of Manchester) for teaching us how to transform Araucaria diagrams into Word/Paint diagrams, as well as to our reviewers for helpful suggestions.

${ }^{7}$ In this paper, following Walton et al (2008) and their typology of argument schemes, we have used a version of Araucaria for visualising the structure of argument. Araucaria is a software tool for representing arguments, developed by Chris Reed and Glenn Rowe (2005) at the University of Dundee. There are of course other methods for diagramming arguments and showing relationships between premises and conclusions. In pragma-dialectics, practical reasoning is briefly subsumed under the scheme of causal argumentation, in a three-fold taxonomy that also includes symptomatic and comparison argumentation, and specific critical questions are associated with each. Pragmadialectics uses its own numerical and graphic conventions to indicate relationships between premises and standpoints, and whether argumentation is single, multiple, coordinative or subordinative.

${ }^{8}$ The political field has its own field-specific properties (Ieţcu-Fairclough 2009) which constrain what counts as an admissible argumentative move. In recent years, pragma-dialecticians (van Eemeren 2009, 2010) have studied extensively how argumentative strategic maneuvering is affected by the communicative activity type in which it takes place, by the often highly institutionalized and conventionalized contexts in which it occurs. This has also included analysis of genres or activity types characteristic of the political field: adjudication, negotiation, deliberation and debate. 